[Review Paper]

\title{
Review on Mechanisms of Gas Permeation through Inorganic Membranes
}

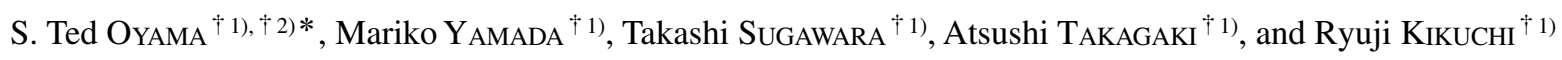 \\ †1) Dept. of Chemical Systems Engineering, The University of Tokyo, 7-3-1 Hongo, Bunkyo-ku, Tokyo 113-8656, JAPAN \\ ${ }^{\dagger 2)}$ Dept. of Chemical Engineering, Virginia Polytechnic Institute \& State University, Blacksburg, VA 24061-0211, USA
}

(Received April 27, 2011)

\begin{abstract}
The major mechanisms of gas permeation through solid membranes are described and the applicable equations describing the permeance are presented. The mechanisms depend on the relative size of the permeating molecules and the diameter of the pores. As pore size decreases the operable mechanisms are Hagen-Pouiselle flow, Knudsen diffusion, surface diffusion, gas-translation, and finally solid-state diffusion. The Hagen-Pouiselle mechanism involves flow through large pores, while the Knudsen mechanism involves collision of molecules with the walls of pores of intermediate size. Surface diffusion deals with movement of molecules trapped in the potential field of the walls of pores of relatively small size, while gas-translation involves molecules that can escape the field, but are constrained by the small pores. Finally, solid-state transport comprises dissolution and transport by diffusion within the solid. These mechanisms are illustrated for hydrogen permeance with the use of two membranes, an alumina membrane with intermediate sized pores and a silica on alumina membrane of dense structure.
\end{abstract}

Keywords

Permeation mechanism, Inorganic membrane, Silica membrane, Solid-state diffusion,

Glassy membranes mechanism, Hydrogen

\section{Introduction}

Common technologies employed for gas separations include solvent absorption, pressure swing adsorption, cryogenic distillation and membrane separation. Compared with other methods, membrane separation technologies have economic potential in reducing operating costs, minimizing unit operations and lowering energy consumption ${ }^{1) \sim 3)}$. For these reasons and because of the increasing demand for high purity gases, the development of effective gas separation membranes has engendered considerable interest in academia and industry ${ }^{4) \sim 6)}$. Desirable characteristics of separation membranes are high hydrogen flux at low pressure drops, tolerance to contaminants, mechanical strength, low cost, and operation at a range of system temperatures ${ }^{7}$. The objective of this review is to describe different mechanisms of permeation in inorganic membranes and the characteristics of these mechanisms. This is an important aspect of membrane development as it allows identification of the limiting steps, and possible means of improving the performance of the membranes. This review will also describe as a concrete example the permeation of hydrogen and other gases through supported silica membranes. This is of interest because the system

\footnotetext{
* To whom correspondence should be addressed.

* E-mail: oyama@vt.edu,ted_oyama@chemsys.t.u-tokyo.ac.jp
}

manifests the contributions of different mechanisms, and provides a tangible illustration of the interplay between different physical processes.

\section{General Considerations and Mechanisms}

In membrane science performance is most commonly associated with two properties, permeability and selectivity, so much work on membrane development has revolved around understanding of these properties. The permeability, $P_{\mathrm{M} i}\left[\mathrm{~mol} \cdot \mathrm{m}^{-1} \cdot \mathrm{s}^{-1} \cdot \mathrm{Pa}^{-1}\right]$, refers to the intrinsic ability of a membrane to allow passage of a species $i$ and relates the molar flux, $N_{i}\left[\mathrm{~mol} \cdot \mathrm{m}^{-2} \cdot \mathrm{s}^{-1}\right]$, to the driving force, which is usually expressed as the difference in pressure or concentration across the membrane. The permeability divided by the thickness, $L$, of the membrane is the permeance $\left[\mathrm{mol} \cdot \mathrm{m}^{-2} \cdot \mathrm{s}^{-1} \cdot \mathrm{Pa}^{-1}\right]$.

$$
\begin{aligned}
& \left.N_{i}=\left(\frac{P_{\mathrm{M} i}}{L}\right) \text { (driving force }\right) \\
& =\bar{P}_{\mathrm{M} i}(\text { driving force })
\end{aligned}
$$

The selectivity is obtained most simply by the ratio of the single-gas permeabilities or permeances. These should be measured at the same conditions.

$$
S_{i, j}=\frac{P_{\mathrm{M} i}}{P_{\mathrm{M} j}}=\frac{\bar{P}_{\mathrm{M} i}}{\bar{P}_{\mathrm{M} j}}
$$




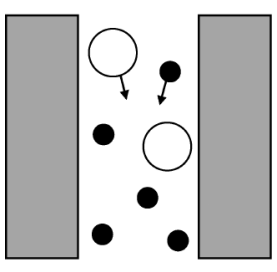

$\rightarrow \quad d_{p} \quad \leftarrow$

(a) Bulk flow

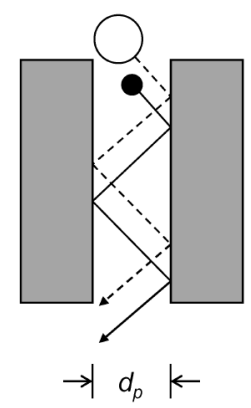

(b) Knudsen diffusion

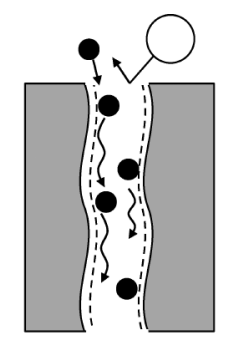

(c) Surface diffusion

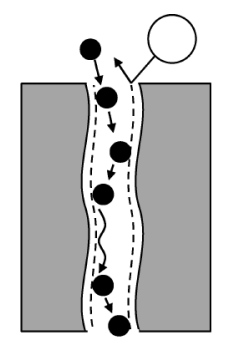

(d) Gas-translational diffusion

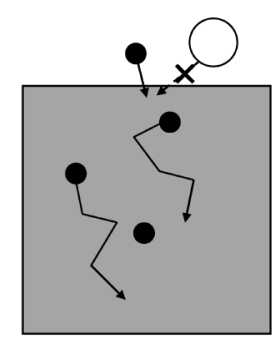

(e) Solid state diffusion

Fig. 1 Various Gas Separation Mechanisms

However, oftentimes the actual selectivity can deviate strongly from that defined above because of interactions between the species with each other or with the walls of the membranes. For example, the preferred adsorption or absorption of one species in the pores of a membrane can block the passage of other species. Thus, single-gas selectivities should be taken as a limiting case approximation.

A fundamental expression for transport in membranes is derived from Fick's First Law, which relates the flux of species $i$ to the concentration gradient. The gradient in turn can be related to the concentration in the inlet, $c_{i \mathrm{o}}$ and outlet, $c_{i \mathrm{~L}}$, of a membrane of thickness $L$ :

$$
\begin{aligned}
& N_{i}=-D_{i}(c) \nabla c_{i} \\
& N_{i}=\frac{D_{e, i}}{L}\left(c_{i \mathrm{o}}-c_{i \mathrm{~L}}\right)
\end{aligned}
$$

The diffusivity in Fick's first law is the ordinary molecular diffusivity, $D_{i}(c)\left[\mathrm{m}^{2} \cdot \mathrm{s}^{-1}\right]$, which may have a concentration dependence. In the case of membranes an effective diffusivity, $D_{\mathrm{e}, i}$ is used, where the porosity $\varepsilon$ and tortuosity $\tau$ of the membrane are included. The tortuosity is a factor that accounts for the increased length of a pore by the presence of twists and turns. For example, if a single straight pore is replaced by one having a single $90^{\circ}$ turn, the tortuosity would be $\sqrt{2}$ or 1.4. In an early treatment the relative diameters of the diffusing molecules, $d_{\mathrm{m}}$, and pores, $d_{\mathrm{P}}$, was taken into account through a restrictive factor $K_{\mathrm{r}}^{8)}$.

$$
\begin{aligned}
& D_{e, i}=\frac{\varepsilon D_{i}}{\tau} K_{\mathrm{r}} \\
& K_{\mathrm{r}}=\left[1-\left(\frac{d_{\mathrm{m}}}{d_{\mathrm{p}}}\right)\right]^{4} \quad\left(d_{\mathrm{m} /} / d_{\mathrm{p}}\right) \leq 1
\end{aligned}
$$

For many membranes $d_{\mathrm{m}} / d_{\mathrm{p}}$ is small, so $K_{\mathrm{r}}$ is unity. There have been many proposed mechanisms with a variety of materials based on various interaction and diffusion processes. These mechanisms are in broad terms distinguished by the ratio of pore diameter $d_{\mathrm{p}}$ to kinetic diameter $d_{\mathrm{m}}$ of the gas molecule. As the pore diameter becomes smaller, that is with increasing value of $d_{\mathrm{m}} / d_{\mathrm{p}}$, the interactions between the molecule and the surface become larger in proportion to the ratio of the area of the surface potential field to the pore volume. Therefore, the state of the permeating gas molecule changes from a "gaseous state" to a "trapped state." It is important to note that, because of the wide range of pore sizes in membranes, the distinction between each mechanism is not always obvious.

Gas transport in membranes can occur through a number of possible mechanisms ${ }^{9)}$. These include bulk Poiseuille flow for large pores, Knudsen diffusion for intermediate size pores, size-restricted diffusion and surface diffusion for small pores, and bulk diffusion for very small pores or no pores ${ }^{10), 11)}$. Sometimes, depending on the conditions and the properties of the permeating molecules, two or more of these processes can occur simultaneously.

\section{1. Hagen-Pouisselle Mechanism}

The Hagen-Pouisselle mechanism is operative when the pore diameter is large compared to the mean free path of the molecules and transport is by bulk fluid flow through the large pores. Assuming that the fluid is Newtonian, the following expression for the average velocity $v\left[\mathrm{~m} \cdot \mathrm{s}^{-1}\right]$, may be derived, where $d_{\mathrm{p}}$ is the diameter of the pore, $\mu\left[\mathrm{kg} \cdot \mathrm{m} \cdot \mathrm{s}^{-1}\right]$ is the viscosity, $l$ is the length of the pore, $p_{\mathrm{o}}$ is the inlet pressure, and $p_{\mathrm{L}}$ is the pressure at a distance $L$.

$$
v=\frac{d_{\mathrm{p}}^{2}}{32 \mu l}\left(p_{\mathrm{o}}-p_{\mathrm{L}}\right)
$$

With suitable manipulation this gives rise to the following expression for the flux

$$
N=\frac{P_{\mathrm{M}}}{L}\left(p_{\mathrm{o}}-p_{\mathrm{L}}\right)
$$

Taking into account the porosity $\varepsilon$ and tortuosity $\tau$ of the membrane, and the pore area per total volume, $a$, which is related to the pore area per membrane volume 
$a_{\mathrm{v}}$, gives the following expressions:

$$
\begin{aligned}
& P_{\mathrm{M}}=\frac{\rho \varepsilon^{3}}{2(1-\varepsilon)^{2} \mu \tau a_{v}{ }^{2}} \\
& a_{v}=\frac{a}{(1-\varepsilon)}
\end{aligned}
$$

\section{2. Knudsen Diffusion Mechanism}

Knudsen diffusion occurs when the pore diameter $d_{\mathrm{p}}$ is smaller than the mean free path $\lambda$ of the gas molecules $^{12)}$. In this regime, collisions occur primarily between gas molecules and the pore wall, rather than between the gas molecules themselves. The collisions are elastic, so there is no tendency for the molecules to interact with the surface, although the direction of rebound is random. The Knudsen diffusivity is obtained from the gas kinetic velocity and geometric parameters associated with the membrane:

$$
D_{\mathrm{K}}=\frac{\varepsilon d_{\mathrm{p}}}{\tau}\left(\frac{8 R T}{9 \mu M}\right)^{1 / 2}
$$

where $\varepsilon$ is the porosity of the membrane, $\tau$ the tortuosity, $R$ the gas constant, $T$ the absolute temperature $[\mathrm{K}]$ and $M$ is the molecular weight of the diffusing gas ${ }^{13)}$.

Gas transport by Knudsen diffusion occurs in the gaseous state without involvement of adsorption because the interaction between diffusing molecules and pore wall is negligibly small. The Knudsen permeance is given by:

$$
\bar{P}_{\mathrm{K}}=\frac{\varepsilon d_{\mathrm{p}}}{\tau L}\left(\frac{8}{9 \pi M R T}\right)^{1 / 2}
$$

where $L$ is the thickness of the membrane.

\section{3. Surface Diffusion Mechanism}

Surface diffusion occurs at low temperatures when gas molecules cannot escape from the surface potential field because the interaction between the inner surface and gas molecules becomes strong compared to their kinetic energy. This mechanism becomes important with relatively small pores because of the relatively high proportion of surface area compared to pore volume. In the surface diffusion mechanism, gas molecules adsorb onto the surface of the membrane at the pore entrance, diffuse through the membrane, and desorb at the pore exit. In the adsorption process, numerous models have been reported in the literature based on different assumptions about the state of the adsorbed gas. In membrane applications for gas separation, adsorption is often well below a monolayer, and so can be described by the Langmuir adsorption model ${ }^{14), 15)}$.

$$
\theta=\frac{q}{q_{\mathrm{s}}}=\frac{K p}{1+K p}
$$

where $\theta$ is the fractional occupancy of adsorption sites, $q$ is the amount of adsorbed gas molecules per unit mass of adsorbent $\left[\mathrm{mol} \cdot \mathrm{kg}^{-1}\right], q_{\mathrm{s}}$ the saturation amount of ad- sorbed molecules [mol $\left.\cdot \mathrm{kg}^{-1}\right], p$ the pressure $[\mathrm{Pa}]$, and $K$ is an adsorption equilibrium constant $\left[\mathrm{Pa}^{-1}\right] . \quad K$ has the following temperature dependency:

$$
K=K_{0} \exp \left(\frac{-\Delta H_{\mathrm{a}}}{R T}\right)
$$

where $\Delta H_{\mathrm{a}}\left[\mathrm{J} \cdot \mathrm{mol}^{-1}\right]$ is the enthalpy of adsorption. Using this equation, the concentration of diffusing gas in the membrane is expressed below when $K p \ll 1$ as:

$$
c=\rho q \approx \rho q_{\mathrm{s}} K p=\rho K_{0} \exp \left(\frac{-\Delta H_{\mathrm{a}}}{R T}\right) p
$$

where $\rho$ is the density of the gas molecule $\left[\mathrm{kg} \cdot \mathrm{m}^{-3}\right]$.

Surface diffusion processes are usually described using a Fickian hopping model. The movement of molecules is visualized as involving jumps of the molecules between adsorption sites along the pore wall surface, passing energy barriers of a given height in the surface $^{16)}$. This results in:

$$
D_{\mathrm{SD}}=\frac{\varepsilon}{\tau} g_{\mathrm{d}} \lambda^{2} v \exp \left(-\frac{\Delta E_{\mathrm{SD}}}{R T}\right)=D_{0} \exp \left(-\frac{\Delta E_{\mathrm{SD}}}{R T}\right)(17)
$$

This equation is derived from the assumption that a molecule makes a jump of length $\lambda[\mathrm{m}]$ and has a velocity $\lambda v\left[\mathrm{~m} \cdot \mathrm{s}^{-1}\right]$ in the right direction given by the probability $g_{\mathrm{d}}$, with $v$ being the jump frequency $\left[\mathrm{s}^{-1}\right]$ of the molecule between adsorption sites and $\Delta E_{\mathrm{SD}}$ is the energy barrier for moving to the other adsorption site. By introducing Eq. (16) and Eq. (17) into Eq. (4):

$$
N_{\mathrm{SD}}=-\frac{D_{\mathrm{SD}}(q) c}{q_{\mathrm{s}}} \frac{\mathrm{d} q}{\mathrm{~d} z}=-\rho K_{0} D_{0}(q) \exp \left(\frac{-\Delta H_{\mathrm{a}}-\Delta E_{\mathrm{SD}}}{R T}\right) \frac{\mathrm{d} p}{\mathrm{~d} z}
$$

Finally one obtains the permeance in the surface diffusion model:

$$
\bar{P}_{\mathrm{SD}}=P_{0} \exp \left(\frac{-\Delta H_{\mathrm{a}}-\Delta E_{\mathrm{SD}}}{R T}\right) \text { where } P_{0}=\frac{\rho K_{0} D_{0}}{L}
$$

with $-\Delta H_{\mathrm{a}}-\Delta E_{\mathrm{SD}}$ being the energy barrier for diffusing molecules to permeate through the membrane. As can be seen, this has a simple Arrhenius equation form. However, the energy term can be positive or negative, depending on the values of $\Delta H_{\mathrm{a}}$ and $\Delta E_{\mathrm{SD}}$. Since the heat of adsorption is a negative quantity, $-\Delta H_{\mathrm{a}}$ is a positive quantity, and if it is larger than the activation energy, the overall exponent can be positive. This would result in permeance decreasing with increasing temperature, and the physical reason would be a decrease in the quantity of adsorbed gas.

\section{4. Gas-translational Mechanism}

The gas translational mechanism occurs with small pore sizes when the diffusing gas molecules have enough kinetic energy to escape the surface potential but cannot readily do so because of the presence of a pore wall on the other side. Considering this, a mechanism which is a combination of the Knudsen diffusion model and the surface diffusion model has been pro- 
posed, called an activated Knudsen diffusion model or gas-translational model (GT model $)^{17) \sim 19)}$. Both surface diffusion and gas-translation have contributions from the surface and so are considered surface flow mechanisms. The gas-translation mechanism has been applied to various materials such as Vycor glass ${ }^{20)}$ and zeolite membranes ${ }^{16), 21)}$. By introducing a probability for diffusion through the micropore, $\rho$ to the Knudsen diffusion model (Eq. (13)), the following equation is obtained.

$$
\bar{P}_{\mathrm{GT}}=\frac{\varepsilon d_{\mathrm{p}} \rho}{\tau L}\left(\frac{8}{\pi M R T}\right)^{1 / 2}
$$

The probability, $\rho$, consists of a pre-exponential, $\rho_{\mathrm{g}}$ and the kinetic energy $\Delta E$ to overcome the diffusion barrier:

$$
\rho=\rho_{\mathrm{g}} \exp \left(-\frac{\Delta E}{R T}\right)
$$

Therefore, the permeance can be expressed as:

$$
\bar{P}_{\mathrm{GT}}=\frac{\varepsilon d_{\mathrm{p}} \rho_{\mathrm{g}}}{\tau L}\left(\frac{8}{\pi M R T}\right)^{1 / 2} \exp \left(-\frac{\Delta E}{R T}\right)
$$

This equation applies to single gases, and does not consider interactions that block pores. It also assumes that the gas diameter is substantially smaller than the pore diameter, so there are no physical blockage effects.

\section{5. Solid-state Diffusion Mechanisms}

Solid-state diffusion occurs with further decrease in the pore size where the gas molecule interacts strongly with the membrane material and its solubility needs to be considered. In this case permeance $=$ solubility $\times$ diffusivity $^{22), 23)}$.

$$
P=S \times D
$$

There are three cases that belong to this class of transport mechanism, permeation through glassy membranes, metallic membranes, and polymeric membranes.

\section{5. 1. Glassy Membranes Mechanism}

For solid-state permeation in glasses (e.g. silica) the molecules permeating through the solid are considered to reside in solubility sites and to be in equilibrium with the gaseous state. The gas molecules in the solubility sites rock at a characteristic vibrational frequency and have to surmount a potential barrier to move to an adjacent solubility site. The behavior of the gas molecules is similar to that in the surface diffusion, but the notion of pore has lost its meaning here. For gas diffusion in fused silica, a statistical model ${ }^{22}$ ) of monatomic gas diffusivity gives:

$$
D_{\mathrm{SS}}=\frac{1}{6}\left(\frac{k T}{h}\right) d^{2} \frac{\left(e^{h v / 2 k T}-e^{-h v / 2 k T}\right)^{3}}{\left(e^{h v^{*} / 2 k T}-e^{-h v^{*} / 2 k T}\right)^{2}} e^{-\frac{\Delta E_{\mathrm{SS}}}{R T}}
$$

constant, $h$ Planck's constant, $d$ the distance between sorption sites in the structure, $T$ the absolute temperature, $v$ the vibrational frequency of gas molecules in the sorption sites, $v^{*}$ the vibrational frequency at the doorway sites, $R$ the gas constant, and $\Delta E_{\mathrm{SS}}$ is the activation energy of diffusion. The solubility, $S\left[\mathrm{~mol} \cdot \mathrm{m}^{-3} \cdot \mathrm{Pa}^{-1}\right]$, in glassy phases is given by ${ }^{24)}$ :

$$
S=\left(\frac{h^{2}}{2 \pi m k T}\right)^{3 / 2} \times \frac{1}{k T} \frac{N_{\mathrm{S}}}{N_{\mathrm{A}}}\left(\frac{e^{-h v / 2 k T}}{1-e^{-h v / k T}}\right)^{3} e^{-\frac{E(0)}{R T}}
$$

where $m$ is the mass of the molecule, $N_{\mathrm{S}}$ the number of solubility sites available per $\mathrm{m}^{3}$ of glass volume, $N_{\mathrm{A}}$ Avogadro's number, and E(0) is the binding energy of the physically dissolved gas molecule in an interstitial sorption site. The solid-state permeance is obtained by using these two equations including the thickness of the separation layer, $L[\mathrm{~m}]$ :

$$
\bar{P}_{S S}=\frac{d^{2} h^{2}}{6 L}\left(\frac{1}{2 \pi m k T}\right)^{3 / 2} \times \frac{N_{S}}{N_{\mathrm{A}}} \frac{1}{\left(e^{h v^{*} / 2 k T}-e^{-h v^{*} / 2 k T}\right)^{2}} e^{-\frac{\Delta E S S}{R T}}
$$

where the $\Delta E_{\mathrm{SS}}$ is the activation energy for the permeation. In the case of polyatomic molecules, a rotational factor is also needed to express the state in the solubility site. The final equation is presented below ${ }^{24)}$ :

$$
\bar{P}_{S S}=\frac{d^{2} h^{2}}{6 L}\left(\frac{1}{2 \pi m k T}\right)^{3 / 2}\left(\frac{\sigma h^{2}}{8 \pi^{2} J k T}\right)^{\alpha} \times \frac{N_{S}}{N_{\mathrm{A}}} \frac{1}{\left(e^{h v^{*} / 2 k T}-e^{-h v^{*} / 2 k T}\right)^{2}} e^{-\frac{\Delta E S S}{R T}}
$$

where $\sigma$ is the symmetry number of the diffusing molecules and $I$ the moment of inertia. The value $\sigma=2$ applies in the case of hydrogen, and the exponent, $\alpha$, accounts for incomplete loss of rotation.

\section{5. 2. Metallic Membranes Mechanism}

The metallic membrane mechanism occurs where a diffusing species is dissolved in a metal. The most common system is that of hydrogen in palladium and its alloys. The flux of hydrogen in palladium membranes is commonly described by Sieverts' law ${ }^{25), 26)}$, where $\pi$ is a diffusion coefficient, $P_{\mathrm{F}}$ is the feed $\mathrm{H}_{2}$ pressure, $P_{\mathrm{P}}$ is the permeate $\mathrm{H}_{2}$ pressure, and the exponent $n$ is 0.5 . This accounts for permeance in thick membranes where the limiting process is diffusion of hydrogen atoms across the bulk.

$$
N_{\mathrm{H}_{2}}=\pi_{\mathrm{H}_{2}}^{(n)}\left(P_{\mathrm{F}}^{n}-P_{\mathrm{P}}^{n}\right)
$$

Oftentimes exponents between 0.5 and 1 are observed, and this is because the overall flux is governed by a combination external transport, surface processes, and bulk diffusion ${ }^{27)}$. Drioli and coworkers explain that when these steps are taken into account the following equation arises.

$$
N_{\mathrm{H} 2}=\pi_{\mathrm{H} 2}^{\text {Diff }}\left[\left(P_{\mathrm{F}}^{0.5}-P_{\mathrm{P}}^{0.5}\right)+a(T)\left(\frac{1}{2}+\frac{b}{T}\right)\left(P_{\mathrm{F}}-P_{\mathrm{P}}\right)\right]
$$

where $D_{\mathrm{Ss}}$ is the solid-state diffusivity, $k$ is Boltzmann's 


$$
a(T)=a_{0} \exp \left(\frac{\Delta E_{\mathrm{A}}}{2 R T}\right)
$$

Clearly the above expression for the flux accounts for the observed exponents even if an explicit expression for $n$ cannot be obtained.

\section{5. 3. Polymeric Membranes Mechanism}

The solution-diffusion mechanism is commonly used to describe permeation in polymers. Wijmans and Baker provide a review ${ }^{28)}$. A plot of permeability of various alkanes in a rubbery polymer versus the vapor pressure of the alkanes shows a maximum (Fig. 2). An equation presented by the authors for the permeability coefficient of gases provides an explanation.

$$
P_{i}=\frac{D_{i} \gamma_{i}}{\gamma_{i(m)} p_{i \text { sat }}}
$$

where $D_{i}$ is the diffusion coefficient, $\gamma_{i}$ is the affinity of the permeant for the gas phase, $\gamma_{i(m)}$ is the affinity of the permeant for the membrane, and $p_{i \text { sat }}$ is the saturation vapor pressure.

The results are due to the decrease of both the saturation pressure of the permeant and the diffusion coefficient with increasing molecular weight which create competing effects on the permeability coefficient. In glassy polymers the decrease in diffusion coefficient dominates other effects, but in rubbery polymers the effects are more balanced. For molecular weights up to 100 permeabilities increase because $p_{i \text { sat }}$ dominates but above molecular weights of 100 the diffusivity becomes more important. This is illustrated for sim-

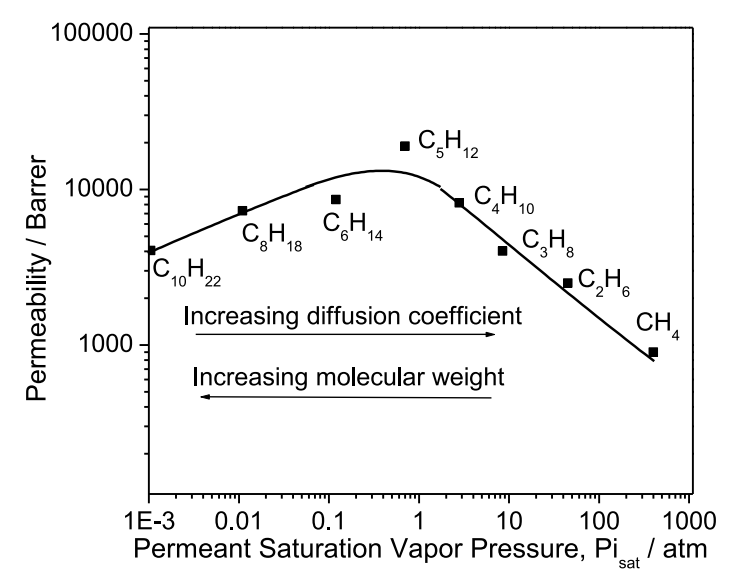

Fig. 2 Permeability Coefficient of $n$-Alkanes in Polydimethylsiloxane as a Function of Saturation Pressure (adapted from Wijmans and Baker) ple alkanes in a silicone rubber membrane.

\section{Application of Membrane Theory in the Study of Membranes for Hydrogen Production}

The previous section provided a summary of the various mechanisms of permeation through inorganic membranes. In the following sections examples will be presented that illustrate the application of membrane theory to the understanding of permeance in membranes. The results obtained with two membranes will be treated in depth to provide tangible examples. The first is a membrane consisting of a $\gamma$-alumina layer placed on top of a porous $\alpha$-alumina support which will be denoted Membrane I. The second is a membrane in which a thin, amorphous silica film is deposited on top of the first membrane, and thus, in which the $\gamma$-alumina portion servers as an intermediate layer, which will be called Membrane II. The synthesis of both membranes followed the procedures described by $\mathrm{Gu}$ and Oyama ${ }^{29), 30)}$ and is presented in the appendix. Briefly, Membrane I utilized a commercial $\alpha$-alumina support with outer pore size of nominal size $5 \mathrm{~nm}$. The layer of $\gamma$-alumina was placed on this support by dip-coating a boehmite sol of particle size $40 \mathrm{~nm}$ and then calcining. Membrane II had a permselective silica layer placed on top of the first membrane by chemical vapor deposition of tetraethylorthosilicate at high temperature $(873 \mathrm{~K})$. The permeance and selectivity of both membranes are reported in Table 1. They illustrate the well-known tradeoff between permeance and selectivity.

The application of the membranes is in hydrogen separation. Hydrogen has attracted considerable attention as an energy carrier for next generation energy delivery systems because it emits no carbon dioxide. To realize a hydrogen energy society, it is necessary to develop effective and safe hydrogen production methods, and for this reason membranes are important possibilities that are being considered. Recent reviews are available for palladium ${ }^{31)}$ and silica ${ }^{32)}$ membranes which are the most studied hydrogen separation membranes, and the materials will not be covered here.

Figure 3 displays scanning electron microscopy (SEM) images of the cross-sections of the $\gamma$-alumina support a) and the prepared membrane b), and a schematic representation of the structure $c$ ). From comparison of the images of a) and b), the intermediate

Table $1 \mathrm{H}_{2}$ Permeance and Selectivity of Membranes I and II

\begin{tabular}{lcc}
\hline & $\begin{array}{c}\mathrm{H}_{2} \text { permeance } \\
{\left[\mathrm{mol} \cdot \mathrm{m}^{-2} \cdot \mathrm{s}^{-1} \cdot \mathrm{Pa}^{-1}\right]}\end{array}$ & $\begin{array}{c}\mathrm{H}_{2} \text { selectivity } \\
\mathrm{H}_{2} / \mathrm{N}_{2}\end{array}$ \\
\hline Membrane I with $\gamma$ - $\mathrm{Al}_{2} \mathrm{O}_{3}$ intermediate layer & $3.3 \times 10^{-5}$ & 3.3 \\
Membrane II with permselective silica on $\gamma-\mathrm{Al}_{2} \mathrm{O}_{3}$ & $8.3 \times 10^{-8}$ & 300 \\
\hline
\end{tabular}



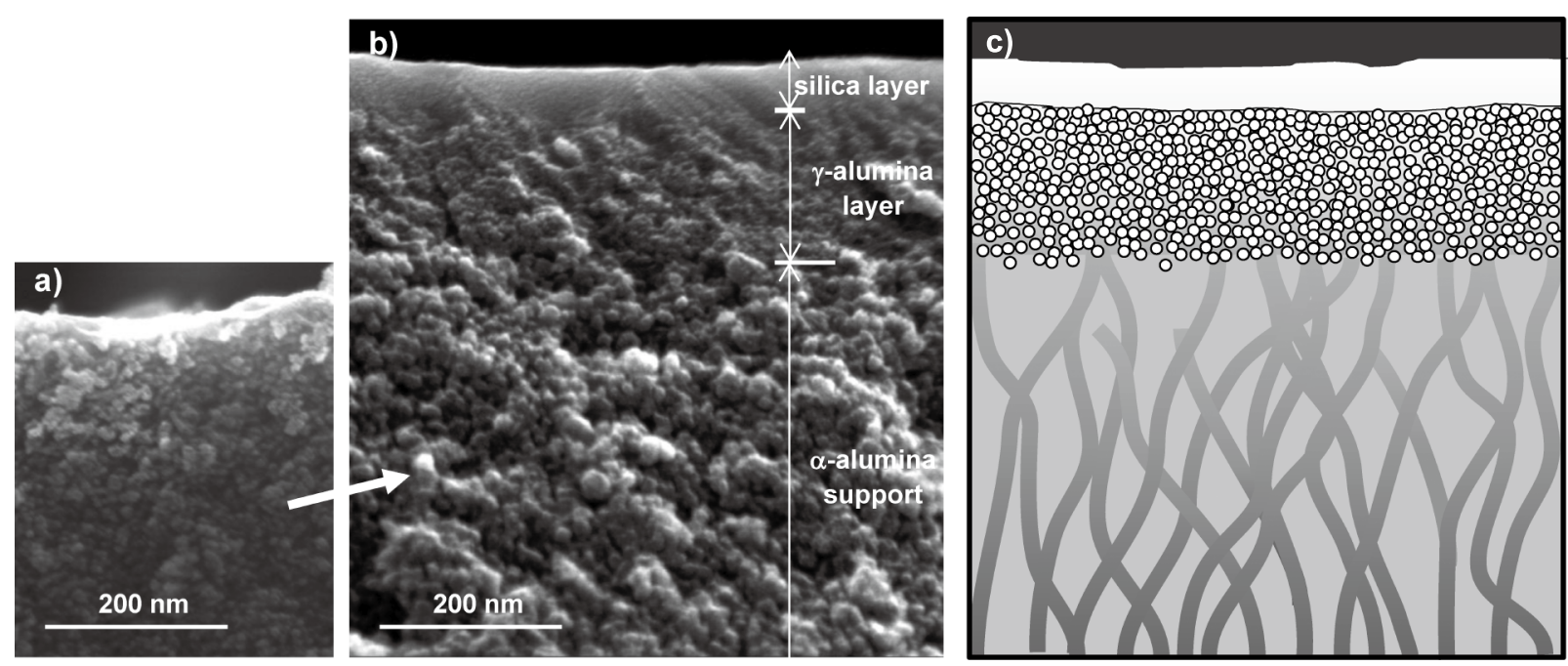

a) Membrane I ( $\gamma$-alumina support) $(\times 150,000)$, b) Membrane II (silica membrane on alumina substrate) $(\times 150,000)$, c) Schematic diagram of the Membrane II structure.

Fig. 3 Scanning Electron Micrographs

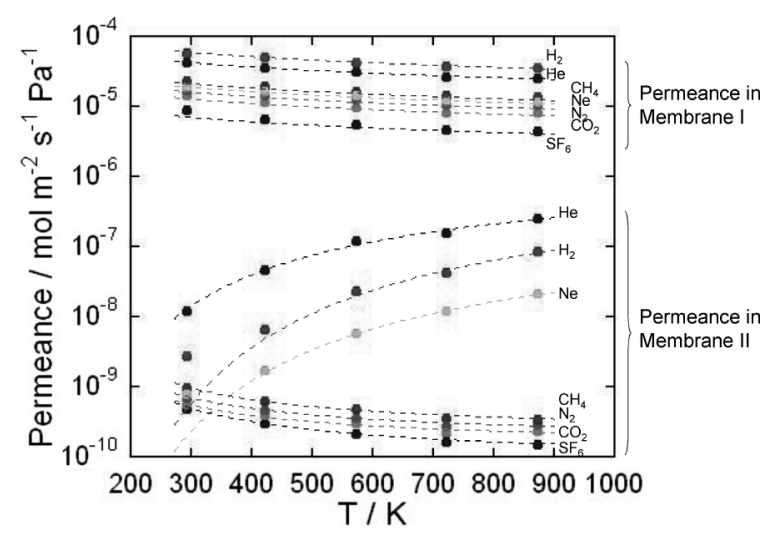

Fig. 4 Experimental Results of Permeance in Membrane I with the Intermediate Alumina Layer and Membrane II Composed of Silica on Alumina

$\gamma$-alumina can be discerned as a thin $170 \mathrm{~nm}$ layer comprised of particles slightly smaller and darker than the particles of the support. The silica layer at the very top is about $50 \mathrm{~nm}$ in thickness.

The temperature dependence of the permeance for both Membranes I and II was different and showed dramatic differences (Fig. 4). For Membrane I with the intermediate alumina layer (Fig. 4, top set of curves) the permeance was high for all gases and decreased with increasing temperature. For Membrane II, the silica membrane on the alumina substrate (Fig. 4, bottom set of curves), the overall permeance was lower, and the behavior depended on the size of the species. For the three smallest gas species $\left(\mathrm{He}, \mathrm{H}_{2}\right.$ and $\mathrm{Ne}$ ) the permeance rose with temperature, while for the other gases the permeance fell with temperature.

\section{1. Permeation in the Intermediate Alumina Layer}

The permeance in Membrane I with the intermediate layer (Fig. 4, top) will be considered first. At atmospheric pressure and room temperature, the mean free paths $\lambda$ of $\mathrm{H}_{2}, \mathrm{~N}_{2}$ and $\mathrm{CO}_{2}$ are 110,60 and $55 \mathrm{~nm}$, respectively, calculated from the Eq. (32):

$$
\lambda=\frac{k T}{\sqrt{2} \sigma p}
$$

where $\sigma$ is the collision cross-section $\left[\mathrm{nm}^{2}\right]$. Since the SEM results indicate that the pore diameter of the intermediate alumina layer is less than that of the support of $5 \mathrm{~nm}, \lambda$ is large compared to the pore diameter, and Knudsen diffusion is expected to prevail in the intermediate layer.

From Eq. (13), gas transport by the Knudsen mechanism should have an inverse square root dependence on temperature and molecular weight of the diffusing gas molecule. Figure 5 duly demonstrates that the permeance depends on $1 / \sqrt{T}$. Table 2 shows the good agreement between permeance ratio $P_{\mathrm{H}_{2}} / P_{i}$ and the theoretical $\sqrt{M_{i} / M_{\mathrm{H}_{2}}}$ value for the Knudsen model at the highest $(873 \mathrm{~K})$ and the lowest $(293 \mathrm{~K})$ temperature. A small discrepancy is seen with the largest molecules at the lower temperature, with the deviation in the ratio indicating higher permeance of the heavier molecules. This suggests the possible contribution of a surface flow mechanism $^{33)}$. Surface flow is expected to increase as the temperature decreases since the adsorption coverage of these larger species on the surface of the pores will increase. This will be discussed later.

From the Knudsen equation the value of the group $\overline{P_{i}} \sqrt{M_{i} T}=\left(\varepsilon d_{\mathrm{p}} / \tau L\right) \sqrt{8 / 9 \pi R}$ should be constant re- 


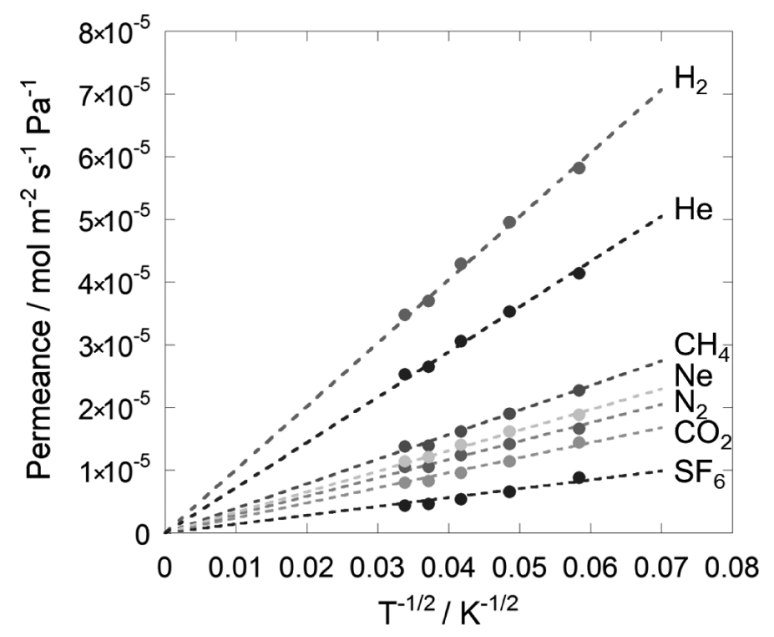

Fig. 5 Permeance vs. Inverse Square Root of Temperature for Membrane I with the Intermediate Alumina Layer

Table 2 Comparison for Membrane I with the Intermediate Alumina Layer between the Experimental Permeance Ratio $\bar{P}_{\mathrm{H}_{2}} / P_{i}$ (at 293 and $823 \mathrm{~K}$ ) and the Knudsen Ratio $\sqrt{M_{i} / M_{\mathrm{H}_{2}}}$

\begin{tabular}{cccccccc}
\hline & \multicolumn{7}{c}{$\mathrm{Gas}$} \\
\cline { 2 - 8 } & $\mathrm{He}$ & $\mathrm{H}_{2}$ & $\mathrm{Ne}$ & $\mathrm{CH}_{4}$ & $\mathrm{~N}_{2}$ & $\mathrm{CO}_{2}$ & $\mathrm{SF}_{6}$ \\
\hline$\sqrt{M_{i} / M_{\mathrm{H}_{2}}}$ & 1.4 & 1.0 & 3.2 & 2.8 & 3.7 & 4.7 & 8.5 \\
$823 \mathrm{~K}$ & 1.4 & 1.0 & 3.1 & 2.5 & 3.3 & 4.4 & 8.0 \\
$293 \mathrm{~K}$ & 1.4 & 1.0 & 3.1 & 2.6 & 3.5 & 4.0 & 6.6 \\
\hline
\end{tabular}

gardless of gas species. The permeance data was fitted to the Knudsen permeance model by the LevenbergMarquardt method and the value of the group $\overline{P_{i}} \sqrt{M_{i} T}$ $=4.6 \times 10^{-5}\left[\mathrm{~mol} \cdot \mathrm{m}^{-2} \cdot \mathrm{s}^{-1} \cdot \mathrm{Pa}^{-1} \cdot(\mathrm{kg} \cdot \mathrm{K})^{1 / 2}\right]$ was obtained. Using this constant the permeance of gas molecules was calculated and the results are shown by the dotted lines in Fig. 4. Using the geometric parameters of alumina, $\varepsilon=0.40^{34)}$ and $\tau=2$, and the observed value of $L=170 \mathrm{~nm}$ presented above, $d_{\mathrm{p}}$ was estimated to $2.1 \mathrm{~nm}$. This indicates that the intermediate layer is successfully formed on the support decreasing the outer pore diameter from $5 \mathrm{~nm}$ in the support to $\sim 2 \mathrm{~nm}$.

\section{2. Permeation in the Silica Layer}

The permeance of the silica layer can be obtained by subtracting the resistance of Membrane I (with the intermediate alumina layer) from the resistance of Membrane II (with the silica layer on the alumina substrate):

$$
\frac{1}{\bar{P}_{\mathrm{SiO}_{2} \text { layer }}}=\frac{1}{\bar{P}_{\text {Membrane II }}}-\frac{1}{\bar{P}_{\text {Membrane I }}}
$$

The temperature dependence of the permeance is shown in Fig. 6. The permeance of Membrane $I$ is greater than two orders of magnitude than Membrane II for all gases, so the results are not greatly different from those of Fig. 4. Thus, the silica layer controls the permeance in Membrane II and the results on the silica layer

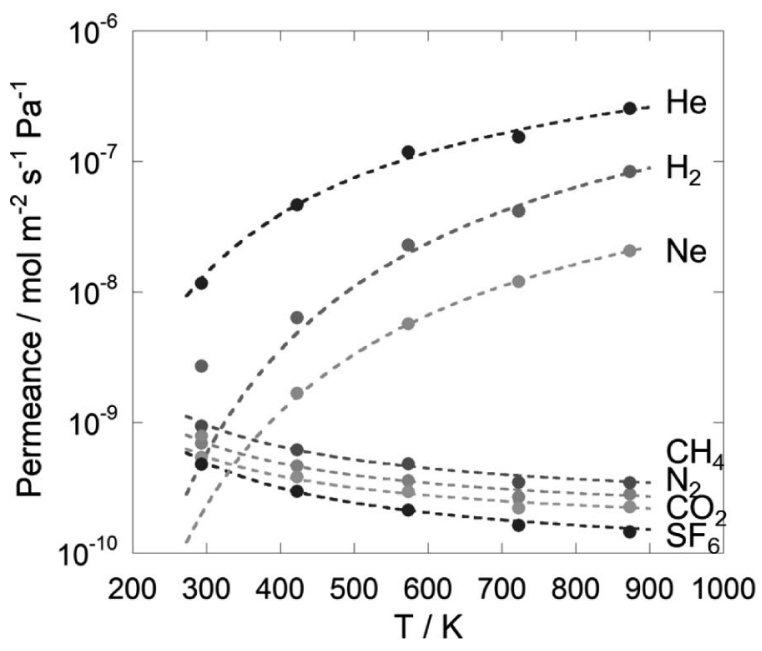

Fig. 6 Permeance in the Silica Layer

are in essence those of that membrane. The data again displays a broad divergence in gas transport between small molecules ( $\mathrm{He}, \mathrm{H}_{2}$ and $\mathrm{Ne}$ ) and large molecules $\left(\mathrm{CH}_{4}, \mathrm{~N}_{2}, \mathrm{CO}_{2}\right.$ and $\left.\mathrm{SF}_{6}\right)$, which have different kinetic diameters ${ }^{35)}$.

First the data for the small molecules will be discussed. The order of permeance $\mathrm{He}>\mathrm{H}_{2}>\mathrm{Ne}$ is strange because it does not follow neither mass nor kinetic diameter. This is contrary to established mechanisms in porous materials. However, the results can be explained by the solid-state permeation mechanism for glassy materials.

The gas permeance on the silica layer was analyzed using the solid state diffusion model (Eq. (27)). The silica layer thickness, $L$ used for the calculation was $50 \mathrm{~nm}$ as obtained from the SEM data (Fig. 3). For the jump distance, $d=0.8 \mathrm{~nm}^{36)}$ was used. The vibrational frequency, $v^{*}$, of each gas species, the activation energy for solid-state permeation, $\Delta E_{\mathrm{SS}}$, and the number of solubility sites, $N_{\mathrm{S}}$, available for each gas species were calculated. The model fitting was again carried out using the Levenberg-Marquardt method. The fitting results are shown by the dotted lines in Fig. 6. There is excellent agreement between the model analysis and the experimental data for the He permeance and very good agreement in the $\mathrm{H}_{2}$ and Ne permeance except at $293 \mathrm{~K}$. The best-fit parameter values are summarized in Table 3. The overall fits are very good with an average regression coefficient of 0.990 . An inverse relation is found between the vibrational frequency with order of $\mathrm{H}_{2}>\mathrm{He}>\mathrm{Ne}$ and the molecular weight. This can be easily understood from a classical oscillator model since heavier molecules will have smaller vibrational frequency. On the other hand, the activation energies were in the order of decreasing kinetic diameter. This also can be understood, as molecules with large kinetic diameter face a large barrier to squeeze through the silica rings. Finally the number of solubil- 
ity sites $N_{\mathrm{S}}$ is largest for the smallest species. This is because on average there will be more sites capable of accommodating the smaller molecules. In summary, the solid-state diffusion model was able to account for gas transport in the silica layer with physically realistic parameters of $v^{*}, N_{\mathrm{S}}$ and $E_{\mathrm{Ss}}$. The slight deviation of the experimental data in the $\mathrm{H}_{2}$ and Ne permeance at $293 \mathrm{~K}$ from the calculations is attributed to the contribution of surface flow. This will be discussed later.

The structure of vitreous silica has been described as a disordered form of $\beta$-cristobalite that contains $5,6,7$, and 8 membered rings with size approximately $0.3 \mathrm{~nm}$ in diameter ${ }^{37) \sim 40)}$. The silica layer in this work probably has a similar structure, and this explains the preferred selectivity of this membrane for small gas molecules over large molecules. However there are probably a small number of small pores (defects) through which even large molecules can pass. Gas transport of large molecules occurs through these pores, while transport of small molecules is dominated by solid state diffusion through the silica.

For the large molecules, permeance decreases with temperature. A likely explanation for this result is that there are a few small pores in the silica layer and that the large molecules can permeate through a surface flow process such as surface diffusion (Eq. (19)) or gastranslation (Eq. (20)). The data were plotted in Arrhenius fashion in Fig. 7. The value of $P_{0}$ and the activation energy for permeation $-\Delta H_{\mathrm{a}}-\Delta E_{\mathrm{SD}}$ were obtained from the Arrhenius plot and the values are given in Table 4. The fit is reasonably good with an average regression coeffient of 0.980 .

Usually the activation energy for surface diffusion is about one-half that of the heat of adsorption, so $\Delta E_{\mathrm{SD}}$ is small, and the overall activation energy for permeation $-\Delta H_{\mathrm{a}}-\Delta E_{\mathrm{SD}}$ is considered to be proportional to the heat of liquefaction (or heat of vaporization $\Delta H_{\mathrm{vap}}$ ).
Table 4 also includes $\Delta H_{\text {vap }}$ values of gases. Although there is general agreement in the trend of $-\Delta H_{\mathrm{a}}-\Delta E_{\mathrm{SD}}$ and $\Delta H_{\text {vap }}$ for $\mathrm{CH}_{4}, \mathrm{~N}_{2}$, and $\mathrm{SF}_{6}, \mathrm{CO}_{2}$ deviates. Since $\mathrm{CO}_{2}$ is a condensable gas and likely to move by surface diffusion, this deviation indicates that the mechanism of permeation is not surface diffusion. Furthermore the most condensable gases $\mathrm{CO}_{2}$ and $\mathrm{SF}_{6}$ have the lowest permeance, which is evidence against surface diffusion. Thus, although the Arrhenius plot data fit theoretical expectations (Eq. (19)), the conclusion is that surface diffusion is not the mechanism of permeation for these large gases.

It is noted that the order of permeance of the four large gases is $\mathrm{CH}_{4}>\mathrm{N}_{2}>\mathrm{CO}_{2}>\mathrm{SF}_{6}$, which is in the order of molecular weight. Therefore, a mass dependence needs to be considered and this is provided by the gas-translation (GT) mechanism, a combination of Knudsen diffusion and surface diffusion. In this case Eq. (22) is simply expressed as the Eq. (34):

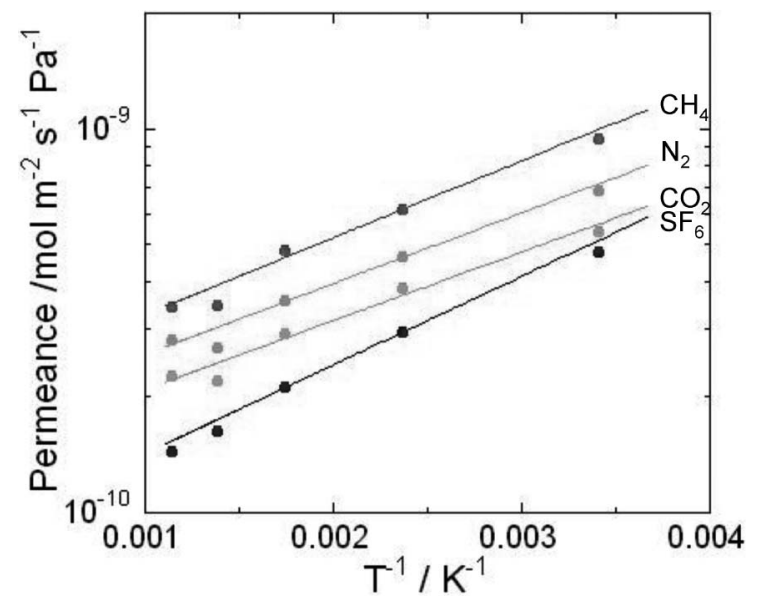

Fig. 7 Arrhenius Plot of Permeance by Surface Diffusion for Membrane II (silica layer)

Table 3 Values of the Parameters for the Statistical Model Analysis for Membrane II (silica layer)

\begin{tabular}{ccccccc}
\hline Gas & $\begin{array}{c}M \\
{\left[\mathrm{~g} \cdot \mathrm{mol}^{-1}\right]}\end{array}$ & $\begin{array}{c}\text { Kinetic diameter } \\
{[\mathrm{nm}]}\end{array}$ & $\begin{array}{c}v^{*} \\
{\left[\mathrm{~s}^{-1}\right]}\end{array}$ & $\begin{array}{c}\Delta E_{\mathrm{SS}} \\
{\left[\mathrm{kJ} \cdot \mathrm{mol}^{-1}\right]}\end{array}$ & $\begin{array}{c}N_{\mathrm{S}} \\
{\left[\mathrm{m}^{-3}\right]}\end{array}$ & $\begin{array}{c}\text { Regression } \\
\text { coefficient }\end{array}$ \\
\hline $\mathrm{He}$ & 4.00 & 0.260 & $6.2 \times 10^{-11}$ & 8.9 & $7.1 \times 10^{-24}$ & 0.983 \\
$\mathrm{H}_{2}$ & 2.02 & 0.289 & $7.9 \times 10^{-11}$ & 17 & $4.0 \times 10^{-24}$ & 0.992 \\
$\mathrm{Ne}$ & 20.2 & 0.275 & $3.9 \times 10^{-11}$ & 15 & $6.3 \times 10^{-24}$ & 0.998 \\
\hline
\end{tabular}

Table 4 Parameters for the Surface Diffusion Model Analysis for Membrane II (silica layer)

\begin{tabular}{ccccccc}
\hline Gas & $\begin{array}{c}M \\
{\left[\mathrm{~g} \cdot \mathrm{mol}^{-1}\right]}\end{array}$ & $\begin{array}{c}\text { Kinetic diameter } \\
{[\mathrm{nm}]}\end{array}$ & $\begin{array}{c}P_{0} \\
{\left[\mathrm{~mol} \cdot \mathrm{m}^{-2} \cdot \mathrm{s}^{-1} \cdot \mathrm{Pa}^{-1}\right]}\end{array}$ & $\begin{array}{c}\Delta H_{\mathrm{a}}-\Delta E_{\mathrm{SD}} \\
{\left[\mathrm{kJ} \cdot \mathrm{mol}^{-1}\right]}\end{array}$ & $\begin{array}{c}\text { Regression } \\
\text { coefficient }\end{array}$ & $\begin{array}{c}\Delta H_{\mathrm{vap}} \\
{\left[\mathrm{kJ} \cdot \mathrm{mol}{ }^{-1}\right]}\end{array}$ \\
\hline $\mathrm{CH}_{4}$ & 16 & 0.38 & $2.1 \times 10^{-11}$ & 3.8 & 0.979 & 8.2 \\
$\mathrm{~N}_{2}$ & 28 & 0.364 & $1.7 \times 10^{-11}$ & 3.5 & 0.976 & 5.6 \\
$\mathrm{CO}_{2}$ & 44 & 0.33 & $1.4 \times 10^{-11}$ & 3.4 & 0.974 & $15.9^{\mathrm{a})}$ \\
$\mathrm{SF}_{6}$ & 146 & 0.55 & $0.84 \times 10^{-11}$ & 4.4 & 0.993 & 17.1 \\
\hline
\end{tabular}

a) The heat of liquefaction of $\mathrm{CO}_{2}$ was calculated by the extrapolation of the difference between the enthalpy of liquid and vapor to $1 \mathrm{~atm}$. 
Table 5 Parameters for the Gas-translation Model Analysis for Membrane II (silica layer)

\begin{tabular}{ccccc}
\hline Gas & $\begin{array}{c}M \\
{\left[\mathrm{~g} \cdot \mathrm{mol}^{-1}\right]}\end{array}$ & $C$ & $\begin{array}{c}\Delta E \\
{\left[\mathrm{~kJ} \cdot \mathrm{mol}^{-1}\right]}\end{array}$ & $\begin{array}{c}\text { Regression } \\
\text { coefficient }\end{array}$ \\
\hline $\mathrm{CH}_{4}$ & 16 & $8.58 \times 10^{-8}$ & -1.87 & 0.993 \\
$\mathrm{~N}_{2}$ & 28 & $9.23 \times 10^{-8}$ & -1.63 & 0.989 \\
$\mathrm{CO}_{2}$ & 44 & $9.79 \times 10^{-8}$ & -1.46 & 0.990 \\
$\mathrm{SF}_{6}$ & 146 & $1.05 \times 10^{-7}$ & -2.44 & 0.999 \\
\hline
\end{tabular}

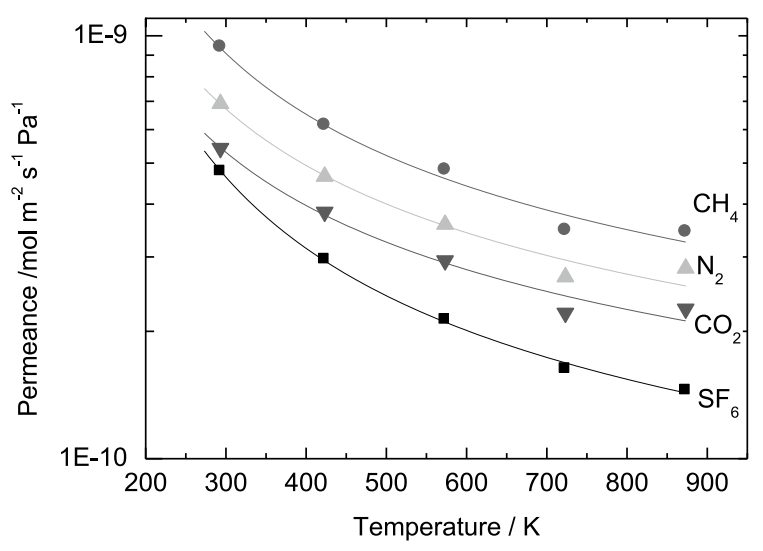

Fig. 8 Gas-translational Analysis of the Permeance of $\mathrm{CH}_{4}, \mathrm{~N}_{2}$, $\mathrm{CO}_{2}$ and $\mathrm{SF}_{6}$ in Membrane II (silica layer)

$$
\bar{P}=\frac{C}{\sqrt{M R T}} \exp \left(-\frac{\Delta E}{R T}\right)
$$

The values of the parameters for the gas-translation model analysis are given in Table 5. There was very good fit to the experimental values as shown in Fig. 8 . The average regression coefficient was 0.993 , which was higher than that obtained with the Arrhenius fit.

Now for the small molecules $\mathrm{H}_{2}$ and $\mathrm{Ne}$, the increase in the permeance at $293 \mathrm{~K}$ noted earlier can now be explained as originating from a contribution of gastranslation through the small pores. This is supported by the fact that the experimental results at $293 \mathrm{~K}$ are different from the other four higher temperatures in Fig. 6. The overall gas transport is summarized in Fig. 9.

To summarize, the structure of Membrane II can be viewed as consisting of a silica layer about $50 \mathrm{~nm}$ in thickness deposited on an $\alpha$-alumina support with an intermediate $\gamma$-alumina layer. The alumina support and intermediate layer constitute Membrane I. The intermediate layer has pores of diameter about $2 \mathrm{~nm}$ and the underlying support of diameter $5 \mathrm{~nm}$. The permeation mechanism through these pores is by Knudsen diffusion. The silica portion shows anomalous results for the permeation of $\mathrm{He}, \mathrm{H}_{2}$, and $\mathrm{Ne}$, because the order does not follow mass or species size, and this gives strong evidence for the solid-state diffusion mechanism. Thus, the silica membrane does not

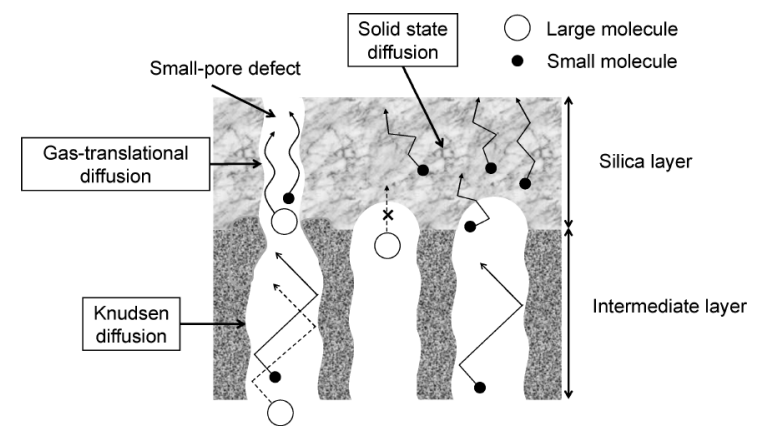

Fig. 9 Schematic of Gas Transport in Membrane II (silica supported on alumina substrate)

have pores, but a network of solubility sites, and permeance of the small gases occurs by jumps between adjacent sites. The silica layer also has a small number of small pores which allow the passage of the larger species, $\mathrm{CH}_{4}, \mathrm{~N}_{2}, \mathrm{CO}_{2}$, and $\mathrm{SF}_{6}$. The temperature and mass dependence of permeance there suggests that the mechanism of transport in these small pores is by gastranslation.

Very recently, the group of Tsuru proposed a novel method for the determination of pore size which they call a normalized Knudsen-based permeance (NKP) derived from the GT model ${ }^{19)}$. The NKP, $f$, is the ratio of the permeance of a target component to that predicted from a reference component $(\mathrm{He})$ based on the Knudsen diffusion mechanism (Eq. (35)). The quantity $\bar{P}_{\mathrm{He}} \sqrt{M_{\mathrm{He}} / M_{i}}$ is the permeance of the target component predicted from the He permeance under the Knudsen diffusion mechanism. Therefore NKP indicates the ratio of permeance between experimental values and predicted values from He by Knudsen diffusion. If the NKP equal 1, the target component behaves according to the Knudsen mechanism. With proposed assumptions including that the activation energies $E$ are the same for any type of gas, the following equations were obtained. Using these, the pore size of the membrane, $d_{\mathrm{p}}$, could be estimated.

$$
\begin{aligned}
& f=\frac{P_{i} \sqrt{M_{i}}}{P_{\mathrm{He}} \sqrt{M_{\mathrm{He}}}} \text { or } P_{i}=f \times P_{\mathrm{He}} \sqrt{\frac{M_{\mathrm{He}}}{M_{i}}} \\
& f=\frac{\left(1-d_{i} / d_{\mathrm{p}}\right)^{3}}{\left(1-d_{\mathrm{He}} / d_{\mathrm{p}}\right)^{3}}
\end{aligned}
$$

Figure 10 plots molecular size against normalized Knudsen-based permeance $(f)$ for the silica membrane. From the results, $d_{\mathrm{p}}$ was numerically fitted using Eq. (36) to be $0.34 \mathrm{~nm}$, which is comparable to that of a sol-gel silica membrane from TEOS ${ }^{11), 19)}$. Although the method can be used for the data obtained here, and gives a reasonable estimate of the pore diameter, if 


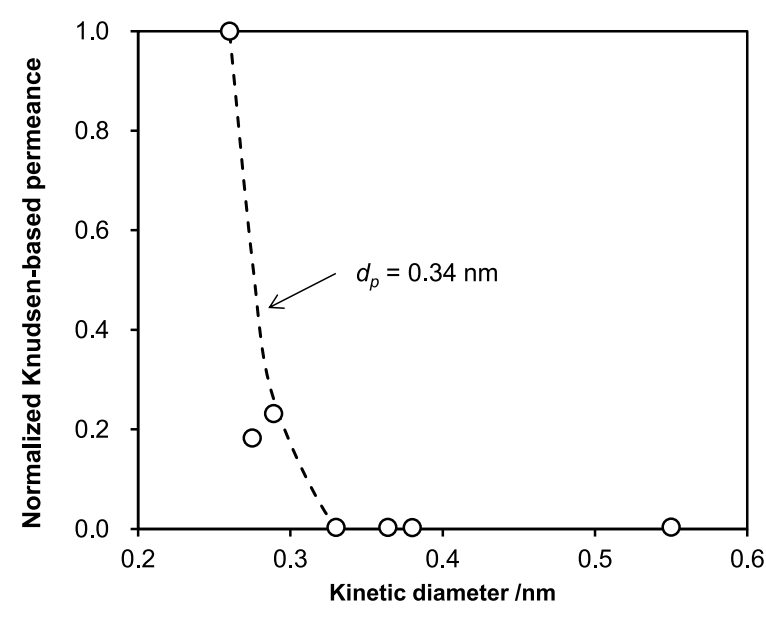

Fig. 10 Analysis by the Tsuru Method of Knudsen-based Permeance against Kinetic Diameter of Gas

there were pores. Indeed, previous work showed that a critical size cutoff for permeance of molecules of different size was about $0.3 \mathrm{~nm}^{24)}$. However, for the reasons outlined above, the silica material is best viewed as not containing classical pores. If it did, the strange order of permeance $\mathrm{He}>\mathrm{H}_{2}>\mathrm{Ne}$, which does not follow mass or species size, could not be explained. Instead, it is best to consider that the amorphous silica network has solubility sites formed by cavities in the siloxane network, and that transport occurs by jumps of the permeating species between these solubility sizes which are of size about $0.3 \mathrm{~nm}$ in diameter and are spaced about $0.8 \mathrm{~nm}$ apart. This view accounts for the temperature, mass, and kinetic diameter dependence of the permeance and gives physically realistic values for the transport parameters, such as number of solubility sites, activation energies, and jump frequencies.

\section{Appendix}

\section{1. Fabrication of Membranes}

The silica membrane used in this study consisted of three layers, an $\alpha$-alumina support, a $\gamma$-alumina intermediate layer, and a silica layer. A porous $\alpha$-alumina tube (Membralox, Pall Corp., i.d. $=7 \mathrm{~mm}$, o.d. $=$ $10 \mathrm{~mm}$, length $=2.8 \mathrm{~cm}$ ) with a nominal outer pore size of $5 \mathrm{~nm}$ was used as a support. For use it was connected to nonporous $\gamma$-alumina tubes at both ends with ceramic joints. The ceramic joints were made with a glass paste fired at $1273 \mathrm{~K}$ for $0.5 \mathrm{~h}$.

The intermediate layer was formed by the dip-coating of boehmite $(\mathrm{AlOOH})$ sols. The boehmite sols were derived from the hydrolysis of aluminum alkoxides and their subsequent acid peptization. A quantity of $0.20 \mathrm{~mol}$ of aluminum isopropoxide was added to $300 \mathrm{~mL}$ of distilled water at room temperature. The mixture was quickly heated to $353 \mathrm{~K}$ and stirred on a magnetic stirrer for $0.5 \mathrm{~h}$ at $353 \mathrm{~K}$ for the hydrolysis of

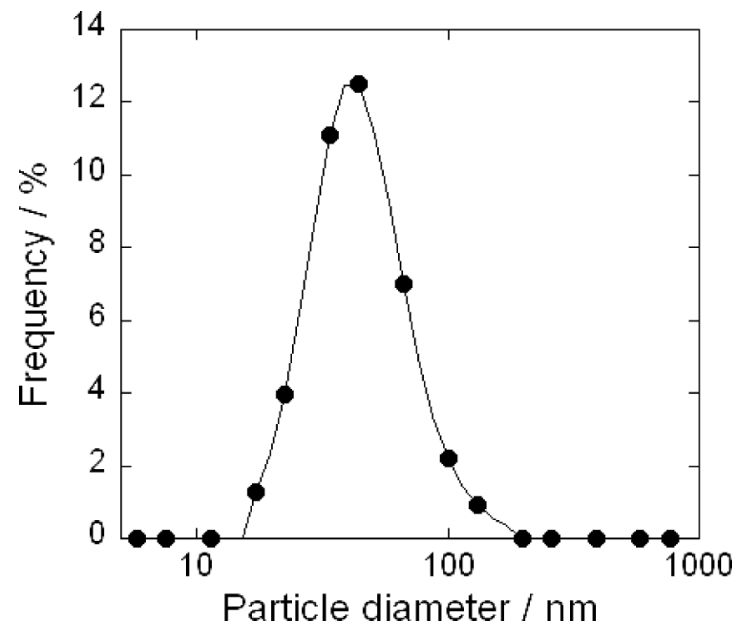

Fig. 11 Particle Diameter Distribution of the Sol Used in the Dipcoating

the isopropoxide and the formation of a boehmite precipitate. A quantity of $0.030 \mathrm{~mol}$ of acetic acid was added to the precipitate and was refluxed at the same temperature for $22 \mathrm{~h}$ to get a clear sol. During this step, the precipitate was peptized by acid to form small colloidal particles. The dipping solution was fabricated by mixing the obtained sols with polyvinyl alcohol solution and distilled water to obtain a $0.15 \mathrm{M}(1 \mathrm{M}=$ $1 \mathrm{~mol} \cdot \mathrm{dm}^{-3}$ ) concentration of the sol and a $0.35 \mathrm{wt} \%$ concentration of PVA. The mean diameter of the obtained sol in the dipping solution was measured by dynamic light scattering with a particle size analyzer (HORIBA, LB-550) and was found to be $40 \mathrm{~nm}$ (Fig. 11). The alumina tube was wrapped in PTFE seal tape so that the intermediate layer was placed only on the inside of the tube and was dipped into the dipping solution for $10 \mathrm{~s}$. After drying the sol in air for some days, the membrane tube was heated to $923 \mathrm{~K}$ in air at a rate of $1 \mathrm{~K} \cdot \mathrm{min}^{-1}$ and calcined for $3 \mathrm{~h}$. During the whole experiment, every heating and cooling step was conducted at the rate of $1 \mathrm{~K} \cdot \mathrm{min}^{-1}$.

The top-most silica layer was placed on the $\gamma$-alumina intermediate layer by a chemical vapor deposition (CVD) method. In this process, a silica compound is thermally decomposed and deposited on the surface of the intermediate layer. Tetraethylorthosilicate (TEOS) was employed as the silica source and the deposition was performed at $873 \mathrm{~K}$ for $4 \mathrm{~h}$. The setup is shown in Fig. 12, and the CVD process parameters are listed in Table 6.

\section{2. Permeation Measurement}

Gas permeation measurements were conducted with various gases $\left(\mathrm{H}_{2}, \mathrm{He}, \mathrm{Ne}, \mathrm{N}_{2}, \mathrm{CH}_{4}, \mathrm{CO}_{2}\right.$ and $\left.\mathrm{SF}_{6}\right)$ in the temperature range of $293-873 \mathrm{~K}$. The measurement gas was introduced to the inside of the membrane tube through one end of the tube with the other side of the tube was closed. The gas permeated to the outside 


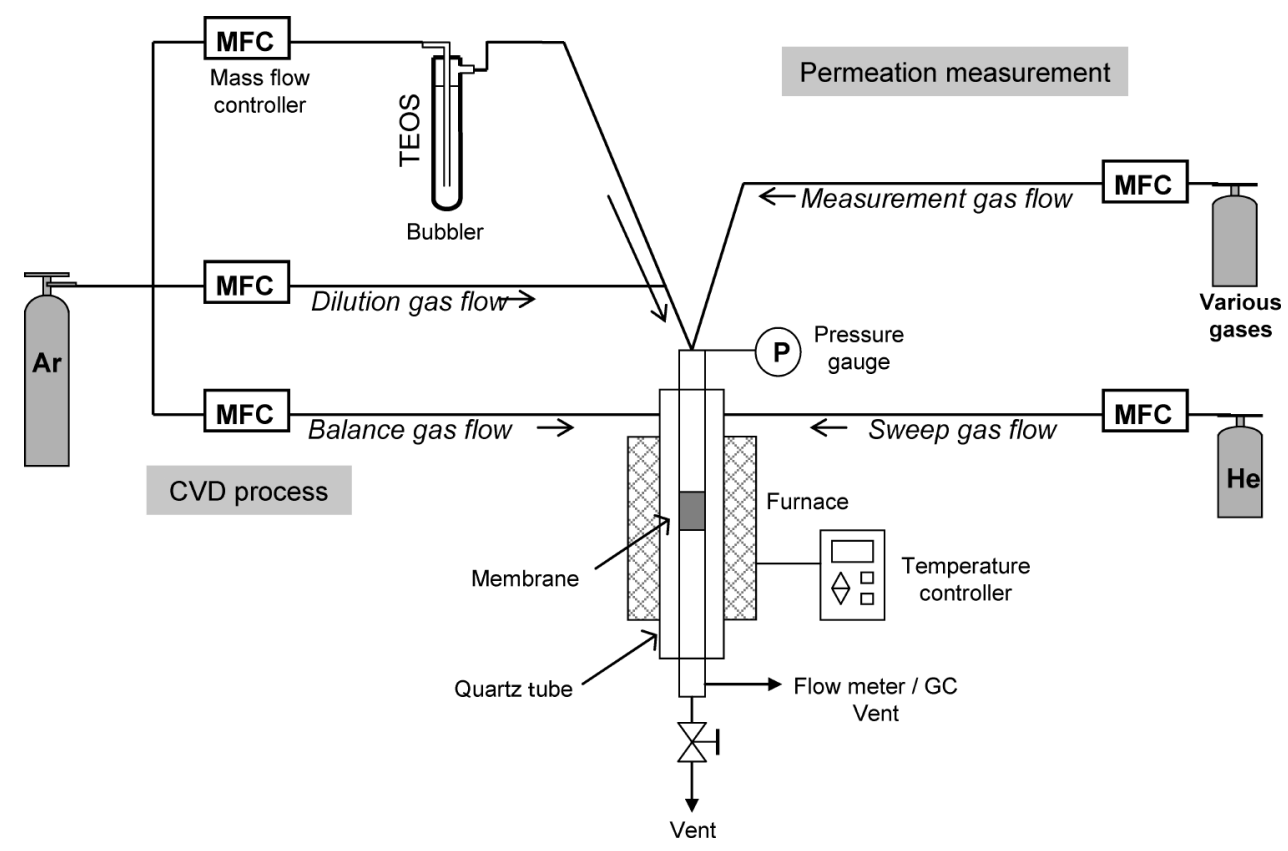

Fig. 12 Schematic of Membrane Fabrication and Permeation Measurement Apparatus

Table 6 Operating Parameters in the CVD Process

\begin{tabular}{lrc}
\hline Carrier gas flow rate & {$\left[\mu \mathrm{mol} \cdot \mathrm{s}^{-1}\right]$} & 4.3 \\
Dilute gas flow rate & {$\left[\mu \mathrm{mol} \cdot \mathrm{s}^{-1}\right]$} & 16 \\
Balance gas flow rate & {$\left[\mu \mathrm{mol} \cdot \mathrm{s}^{-1}\right]$} & 22 \\
Concentration of TEOS in the inner tube & {$\left[\mathrm{mol} \cdot \mathrm{m}^{-3}\right]$} & 0.0186 \\
$\quad$ & & \\
gas flow & {$[\mathrm{K}]$} & 296 \\
Bubbler temperature &
\end{tabular}

Flow rates in $\mu \mathrm{mol} \cdot \mathrm{s}^{-1}$ may be converted to $\mathrm{cm}^{3} \cdot \mathrm{min}^{-1}$ by multiplication by 1.5 .

of the membrane tube and the flow was measured by a soap film flow meter (HORIBA, SF-1U/2U). For very low flow rates a sweep gas at a set flow rate was used and the concentration of the permeate was measured by a gas chromatograph to obtain the permeate flow rate. The permeance of each gas was calculated using the following expression.

$$
P_{i}=\frac{F_{i}}{A \Delta p}
$$

where $P_{i}$ is the permeance $\left[\mathrm{mol} \cdot \mathrm{m}^{-2} \cdot \mathrm{s}^{-1} \cdot \mathrm{Pa}^{-1}\right], F_{i}$ the permeated gas flow rate $\left[\mathrm{mol} \cdot \mathrm{s}^{-1}\right], A$ the surface area $\left[\mathrm{m}^{2}\right]$, and $\Delta p$ is the pressure difference $[\mathrm{Pa}]$ between the inside and the outside of the membrane tube.

\section{Conclusions}

The main permeance mechanisms of gas transport through solid membranes were described. These included the Hagen-Pouiselle, Knudsen, surface diffusion, gas-translation, and solid-state permeation mechanisms. The applicability of each mechanism tracked with the relative size of the permeating molecules and the pore diameter of the membrane. The mechanisms were illustrated through examples of gas permeation through two membranes, an alumina based-material with moderately large pores and a silica-based material with a dense structure. Gas transport through the alumina material was well described by Knudsen diffusion. Gas transport through the silica membrane required a combination of a statistical solid-state diffusion and a gas-translational mechanism. Values for vibrational frequencies, solubility site densities, and activation energies were physically realistic and explained the experimental results.

\section{Acknowledgments}

For support of this work the author acknowledges the Director, National Science Foundation, Division of Chemical, Bioengineering, Environmental, and Transport Systems (CBET) under grant CBET-084316, the National Energy Technology Laboratory under the NETL-RUA program grant, the Ministry of Education, Science, Sports and Culture (MEXT), Grant-in-Aid for Scientific Research (B) (22360335).

\section{References}

1) Li, K., "Ceramic Membranes for Separation and Reaction," Wiley, New York (2008).

2) Malada, R., Menendez, M. (Eds.), "Inorganic Membranes: Synthesis, Characterization and Applications Membrane Science and Technology," Elsevier, Amsterdam (2008).

3) Sanches, J. G., Tsotsis, T. T., "Catalytic Membranes and Membrane Reactors," Wiley-VCH, New York (2002).

4) Oyama, S. T., Stagg-Williams, S. M. (Eds.), “ Inorganic, Polymeric, and Composite Membranes: Structure-Function 
and Other Correlations," Elsevier, Amsterdam (2011).

5) Gade, S. K., Thoen, P. M., Way, J. D., J. Membr. Sci., 316, 112 (2008).

6) Basile, A., Gallucci, F., Tosti, S., "Synthesis, characterization and applications of palladium membranes," eds. by Mallada, R., Menéndez, M., "Membrane Science and Technology," Elsevier, (2008), p. 255-323.

7) NETL Test Protocol, "Testing of hydrogen separation membrane," DOE/NETL-2008/1335.

8) Beck, R. E., Schultz, J. S., Science, 170, 1302 (1970).

9) Dong, J., Lin, Y. S., Kanezashi, M., Tang, Z., J. Appl. Phys., 104, 121301 (2008).

10) Lu, G. Q., Diniz da Costa, J. C., Duke, M., Giessler, S., Socolow, R., Williams, R. H., Kreutz, T., J. Colloid. Interface Sci., 314, 589 (2007).

11) Tsuru, T., J. Sol-gel Sci., Technol., 46, 349 (2008).

12) Knudsen, M., Ann. Phys., 28, 75 (1909).

13) Seader, J. D., Henley, E. J., "Separation Process Principles," 2nd Edition, Wiley, New York (2006).

14) Langmuir, I., J. Am. Chem. Soc., 37, 1139 (1915).

15) Lee, D., Oyama, S. T., J. Membr. Sci., 210, 291 (2002).

16) Burggraaf, A. J., J. Membr. Sci., 155, 45 (1999).

17) Shelekhin, A. B., Dixon, A. G., Ma, Y. H., AIChE J., 41, 58 (1995).

18) Yoshioka, T., Nakanishi, E., Tsuru, T., Asaeda, M., AIChE J., 47, 2052 (2001)

19) Lee, H. R., Kanezashi, M., Shimomura, Y., Yoshioka, T., Tsuru, T., AIChE J., DOI: 10.1002/aic.12501.

20) Shindo, Y., Hakuta, T., Yoshitome, H., Inoue, H., J. Chem. Eng. Jpn., 16, 120 (1983).

21) Xiao, J., Wei, J., Chem. Eng. Sci., 47, 1123 (1992).

22) Masaryk, J. S., Fulrath, R. M., J. Chem. Phys., 59, 1198 (1973).
23) Studt, P. L., Shackelford, J. F., Fulrath, R. M., J. Appl. Phys., 41, 2777 (1970).

24) Oyama, S. T., Lee, D., Hacarlioglu, P., Saraf, R. F., J. Membr. Sci., 244, 45 (2004).

25) Hurlbert, R. C., Konecny, J. O., J. Chem. Phys., 34, 655 (1961).

26) Caravella, A., Barbieri, G., Drioli, E., Chem. Eng. Sci., 63, 2149 (2008).

27) Caravella, A., Scura, F., Barbieri, G., Drioli, E., J. Phys. Chem. $B, 114,6033$ (2010).

28) Wijmans, J. G., Baker, R. W., J. Membr. Sci., 107, 1 (1995).

29) Gu, Y., Oyama, S. T., J. Membr. Sci., 306, 216 (2007).

30) Gu, Y., Oyama, S. T., Adv. Mater., 19, 1636 (2007).

31) Yun, S., Oyama, S. T., J. Membr. Sci., (2011) in press.

32) Khativ, S. J., de Souza, K. R., Noronha, F. B., Oyama, S. T., "Inorganic, Polymeric, and Composite Membranes: StructureFunction and Other Correlations," eds. by Oyama, S. T., StaggWilliams, S. M., Elsevier, Amsterdam (2011).

33) Bai, C., Jia, M.-D., Falconer, J. L., Noble, R. D., J. Membr. Sci., 105, 79 (1995).

34) Topuz, B., Ciftcioglu, M., J. Sol-gel. Sci. Technol., 56, 287 (2010).

35) Breck, D. W., "Zeolite Molecular Sieves: Structure, Chemistry and Use," Wiley, New York (1974).

36) Oyama, S. T., Lee, D., Sugiyama, S., Fukui, K., Iwasawa, Y., J. Mater. Sci., 36, 5213 (2001).

37) Davazoglou, D., Vamvakas, V. E., J. Electrochem. Soc., 150, F90 (2003).

38) Pasquarello, A., Car, R., Phys. Rev. Lett., 80, 5145 (1998).

39) Barrer, R. M., Vaughan, D. E. W., Trans. Faraday Soc., 63, 2275 (1967).

40) Hacarlioglu, P., Lee, D., Gibbs, G. V., Oyama, S. T., J. Membr. Sci., 313, 277 (2008).

要旨

無機膜の気体透過メカニズム

\author{
S. Ted OYAMA ${ }^{\dagger 1)},{ }^{\dagger 2)}$, 山田 真理子 ${ }^{\dagger 1)}$, 菅原 孝 ${ }^{\dagger 1)}$, 高垣 敦 ${ }^{\dagger 1)}$, 菊地 隆司 ${ }^{\dagger 1)}$ \\ $† 1)$ 東京大学大学院工学系研究科, 113-8656 東京都文京区7-3-1 \\ †2) バージニア工科大学化学工学科, Blacksburg, VA 24061-0211, USA
}

膜の気体透過に関する主要なメカニズムとその表現式につい て記述した。透過メカニズムは透過するガス分子径と膜の細孔 径との相互サイズに依存する。細孔径が小さくなるにつれ て, 透過メカニズムはバルク拡散, クヌーセン拡散, 表面拡散, 活性化拡散, 固相拡散へと変化する。それぞれの透過メカニズ ムにおいてガス分子は以下のような振る舞いを示す。(1) バル ク拡散では膜の大きなサイズの細孔内を分子が層流にて透過す る。(2) クヌーセン機構では分子が中間サイズの細孔と衝突し
通過する。（3）表面拡散では分子が比較的小さな細孔の壁のポ テンシャル場にトラップされつつ細孔内を通過する。（4）活性 化拡散では分子はポテンシャル場をのがれるが, 小さな細孔に 束縛される。（5）固相拡散では固体内部へ溶解し, 拡散によっ て輸送される。これらのメカニズムについて, 例として中間サ イズの細孔径を有するアルミナ膜と緻密（ちみつ）な構造から なるシリカ膜の二つの膜を用いて示した。 